\title{
Coronary Angiographic Profile of Patients with Acute Non ST-Segment Elevation Myocardial Infarction with Chronic Kidney Disease
}

C M SHAHEEN KABIR ${ }^{1}$ FAZILA TUN-NESA MALIK ${ }^{2}$, ABDUL MALIK ${ }^{2}$, MMAKSUMULHAQ ${ }^{1}$ SYED DAWOOD $^{2}$ MD. TAIMUR $^{1}$,MD. REZAUL KARIM ${ }^{1}$, MAH-NOOR JAHAN ${ }^{3}$, ELORA SHARMIN ${ }^{4}$

${ }^{1}$ Department of Cardiology, Ibrahim Cardiac Hospital \& Research Institute, ${ }^{2}$ Department of Cardiology, National Heart Foundation Hospital \& Research Institute, ${ }^{3}$ Department of Radiology \& Imaging, Holy Family Red Crescent Medical College \& Hospital, ${ }^{4}$ Department of Cardiology, Bangabandhu Sheikh Mujib Medical University, Dhaka,

Address of Correspondence: Dr. C M Shaheen Kabir, Registrar \& Specialist in Cardiology, Ibrahim Cardiac Hospital \& Research Institute, 122, Kazi Nazrul Islam Avenue, Shahbag, Dhaka-1000, Bangladesh, E-mail: skabir67@yahoo.com

\begin{abstract}
:
Background: Nearly $40 \%$ of patients presenting with Non ST-Segment Elevation Myocardial Infarction (NSTEMI) have Chronic Kidney Disease (CKD). CKD is a powerful predictor of adverse events among NSTEMI patients. CKD is associated with a high prevalence of obstructive coronary artery disease.

Objectives: The purpose of the present study was to evaluate the severity of coronary artery disease in patients with Chronic Kidney Disease presenting with Non ST-Segment Elevation Myocardial Infarction.

Methods: In this prospective observational study a total of 128 patients with NSTEMI were enrolled. They were divided equally in group I (NSTEMI with CKD) and group II (NSTEMI with normal renal function) on the basis of estimated glomerular filtration rate. Patients were considered to have CKD if he/she had documented history of CKD or estimated glomerular filtration rate $<60 \mathrm{~mL} / \mathrm{min} / 1.73 \mathrm{~m}^{2}$. Angiographic severity of CAD was assessed by evaluation of number of involved vessel, site of lesion, \% of stenosis, ACC/AHA lesion classification (Type A, B, C) and TIMI flow grade between the groups.

Results: Patients with CKD were significantly older, with a greater prevalence of hypertension, diabetes mellitus, lower left ventricular ejection fraction, and lower haemoglobin level compared with those without $C K D$. CKD was associated with an increased risk of triple vessel and left main disease.

Conclusion: CKD strongly predicts severe coronary artery disease profile among NSTEMI patients.
\end{abstract}

Key words: Non ST-Segment Elevation Myocardial Infarction; Chronic Kidney Disease; Coronary angiography.

Introduction:

We all know that nearly $40 \%$ of patients presenting with Non ST-Segment Elevation Myocardial Infarction (NSTEMI) have Chronic Kidney Disease (CKD). ${ }^{1} \mathrm{CKD}$ is a powerful predictor of adverse events among NSTEMI patients. ${ }^{2}$ CKD patients have a high prevalence of obstructive coronary artery disease (CAD). The severity of CAD and lesion complexity progressively increased as estimated GFR decreased. ${ }^{3}$ Rapid risk stratification is crucial for appropriate management of these patients and for targeting more potent and invasive therapies for higher risk patients. ${ }^{4}$

Objectives:

To assess the angiographic profile of patients with Non ST-Segment Elevation Myocardial Infarction with Chronic Kidney Disease

Methods:

This study was conducted in the Department of Cardiology of the National Heart Foundation Hospital and Research
Institute, Dhaka, Bangladesh during the period of June 2010 to May 2011. A total of 128 patients with NSTEMI were enrolled. They were divided equally in group I (NSTEMI with CKD) and group II (NSTEMI with normal renal function) on the basis of estimated glomerular filtration rate.

Inclusion criteria:

- Patients of both sexes with Non ST-Segment Elevation Myocardial Infarction with chronic kidney disease $\left(\mathrm{eGFR}<60 \mathrm{~mL} / \mathrm{min} / 1.73 \mathrm{~m}^{2}\right)$ and without chronic kidney disease $\left(\mathrm{eGFR} \geq 60 \mathrm{~mL} / \mathrm{min} / 1.73 \mathrm{~m}^{2}\right.$ )

Exclusion criteria:

- Patients with ST-Segment Elevation Myocardial Infarction

- Patients with unstable Angina

- Patients with prior MI, PCI, CABG, and CHF

- Associated congenital and valvular heart disease 
- Associated Cardiomyopathy

- Patients with End Stage Kidney Disease requiring Renal Replacement Therapy.

- Patients with extremely severe concomitant disease (severe dementia, advanced malignancy).

Acute NSTEMI was diagnosed according to the criteria of the ACCF/AHA. ${ }^{5}$ Chronic kidney disease is defined through a range of estimated glomerular filtration rate (eGFR) values by the National Kidney Foundation Kidney Disease Outcomes Quality Initiative (KDOQI). ${ }^{6}$ Informed written consent was taken from each patient before enrollment. Meticulous history was taken regarding symptoms (chest pain or dyspnoea) and detailed clinical examination was performed. Demographic data and risk factors were recorded for all patients. Patient's baseline 12 lead ECG and Echocardiography were performed. Blood sample was taken for biochemical investigations including Troponin I, CKMB, Random blood glucose, Hb\%, Blood urea, Serum creatinine and Serum fasting lipid profile. Serum creatinine, lean body weight, gender and age were used to determine estimated GFR by Cockcroft and Gault formula. ${ }^{7}$ Patients were stratified into 2 groups according to estimated GFR.

Prior to CAG, patients with CKD were treated with tab Nacetylcystine at a dose of 600-1200 mg orally twice daily, the day before and on the day of procedure and/ inj. $\mathrm{NaHCO} 3+0.9 \%$ saline infusion at a rate of $1.0 \mathrm{ml} / \mathrm{kg} /$ hour for $1 \mathrm{~h}$ before the procedure and continued for $6 \mathrm{~h}$ after the procedure as premedication when LVEFe" $40 \%$ to avoid contrast induced nephropathy. However, only Tab Nacetylcystine was used as premedication when $\mathrm{LVEF}<40 \%$ to avoid volume overload in CKD patients.

Coronary angiogram was performed in all patients and non-ionic iso-osmolar contrast agents (Iodixanol) were used in appropriate cases. Angiographic severity of CAD was assessed by evaluation of number of involved vessel, site of lesion, \% of stenosis, ACC/AHA lesion classification (Type A, B, C) and TIMI flow grade between the groups. This percentage was calculated in the projection where the greatest narrowing would be observed. Significant coronary artery disease was defined as $70 \%$ or more luminal stenosis of major epicardial coronary arteries i.e. LAD, LCX or RCA and their branches or e" $50 \%$ luminal narrowing of the left main coronary artery. Patients were classified as having SVD, DVD, TVD or LMD accordingly. ${ }^{8}$

All necessary approval to perform the study was obtained from the Academic Council of National Heart Foundation Hospital and Research Institute, Dhaka, Bangladesh.

All the data were prospectively collected in a pre-designed data collection form. After processing of all available data, statistical analysis of their significance was done. Obtained data were expressed in frequency, percentage, mean and standard deviation as applicable. Comparison between groups was done by Student's t-test for continuous variables. Categorical data were analyzed by Chi-square test and Fisher's exact test (as appropriate). The whole analyses were done with the help of computer based SPSS (Statistical Programme for Social Science) programme version 16.0. p- value of $<0.05$ was considered as significant.

\section{Results:}

The mean age of group I patients was 60.4 years and 49.9 years for group II patients. Hypertension was the commonest risk factor in both groups (75\% vs. 40.6\%).

The mean left ventricular ejection fraction of group I patients was $54.8 \%$ and $58.5 \%$ for group II patients. The mean value of serum creatinine and estimated glomerular filtration rate was $1.7 \mathrm{mg} / \mathrm{dl}$ and $40.4 \mathrm{ml} / \mathrm{min} / 1.73 \mathrm{~m}^{2}$ respectively in CKD group and $1.0 \mathrm{mg} / \mathrm{dl}$ and $76.3 \mathrm{ml} / \mathrm{min} / 1.73 \mathrm{~m}^{2}$ respectively in non-CKD group. The mean value of $\mathrm{Hb} \%$ was 11.1 and 12.1 $\mathrm{gm} / \mathrm{dl}$ in group I and group II respectively.

Coronary angiographic study showed that the frequency of triple vessel and left main disease was higher in most cases of NSTEMI with CKD than NSTEMI with normal renal function (45.3\% and 10.9\% vs. 21.9\% and 4.7\%). By contrast, single vessel disease was significantly higher (37.5\% vs. 15.6\%) in all patients with normal renal function.

Table-I

Distribution of the demographic profiles between the groups

\begin{tabular}{|c|c|c|c|c|c|}
\hline \multirow[t]{2}{*}{ Age group (years) } & \multicolumn{2}{|c|}{ Group I (n=64) } & \multicolumn{2}{|c|}{ Group II (n=64) } & \multirow[t]{2}{*}{$\mathrm{p}$ value* } \\
\hline & $\mathrm{n}$ & $\%$ & $\mathrm{n}$ & $\%$ & \\
\hline$£ 40$ & 0 & 0 & 11 & 17.2 & \\
\hline $41-50$ & 7 & 11 & 30 & 46.9 & \\
\hline $51-60$ & 29 & 45.3 & 15 & 23.4 & \\
\hline $61-70$ & 20 & 31.2 & 8 & 12.5 & \\
\hline e”71 & 8 & 12.5 & 0 & 0 & \\
\hline Mean \pm SD & \multicolumn{2}{|c|}{$60.4 \pm 8$} & \multicolumn{2}{|c|}{$49.9 \pm 9.3$} & $.001^{\mathrm{S}}$ \\
\hline Range & \multicolumn{2}{|c|}{$45-74$} & \multicolumn{2}{|c|}{$31-70$} & \\
\hline
\end{tabular}

Group I = NSTEMI with CKD, Group II = NSTEMI without CKD, S = Significant

* t-test was done to measure the level of significance 
Table-II

Distribution of risk factors between the groups $(n=128)$

\begin{tabular}{|c|c|c|c|c|c|}
\hline \multirow[t]{2}{*}{ Risk factor } & \multicolumn{2}{|c|}{ Group I (n=64) } & \multicolumn{2}{|c|}{ Group II (n=64) } & \multirow{2}{*}{ p value* } \\
\hline & $\mathrm{n}$ & $\%$ & $\mathrm{~N}$ & $\%$ & \\
\hline \multicolumn{6}{|l|}{ Smoking } \\
\hline Current Smoker & 23 & 35.9 & 23 & 35.9 & $.425^{\mathrm{NS}}$ \\
\hline Ex-smoker & 29 & 45.3 & 7 & 11 & \\
\hline Non-smoker & 12 & 18.8 & 34 & 53.1 & \\
\hline \multicolumn{6}{|l|}{ Hypertension } \\
\hline Yes & 48 & 75 & 26 & 40.6 & $.001^{\mathrm{S}}$ \\
\hline No & 16 & 25 & 38 & 59.4 & \\
\hline \multicolumn{6}{|l|}{ Dyslipidaemia } \\
\hline Yes & 37 & 57.8 & 25 & 39.1 & $.052^{\mathrm{NS}}$ \\
\hline No & 27 & 42.2 & 39 & 60.9 & \\
\hline \multicolumn{6}{|l|}{ Family H/O IHD } \\
\hline Yes & 14 & 21.9 & 14 & 21.9 & $1.000^{\mathrm{NS}}$ \\
\hline No & 50 & 78.1 & 50 & 78.1 & \\
\hline \multicolumn{6}{|l|}{ Diabetes mellitus } \\
\hline Yes & 42 & 65.6 & 17 & 26.6 & $.001^{\mathrm{S}}$ \\
\hline No & 22 & 34.4 & 47 & 73.4 & \\
\hline
\end{tabular}

Group I = NSTEMI with CKD, Group II = NSTEMI without CKD,NS = Not Significant

$\mathrm{S}=$ Significant, ${ }^{*}$ Chi-square test was done to measure the level of significance

Table-III

Distribution of the study patients $(n=128)$ by mean ejection fraction

\begin{tabular}{|c|c|c|c|c|c|}
\hline \multirow[t]{2}{*}{$\overline{\mathrm{LVEF} \%}$} & \multicolumn{2}{|c|}{ Group I (n=64) } & \multicolumn{2}{|c|}{ Group II (n=64) } & \multirow[t]{2}{*}{ p value* } \\
\hline & $\mathrm{n}$ & $\%$ & $\mathrm{n}$ & $\%$ & \\
\hline$£ 40$ & 6 & 9.4 & 0 & 0 & \\
\hline $41-50$ & 10 & 15.6 & 9 & 14.1 & \\
\hline $51-60$ & 36 & 56.2 & 28 & 43.8 & \\
\hline e”61 & 12 & 18.8 & 27 & 42.2 & \\
\hline Mean \pm SD & $54.8 \pm 7.8$ & $58.5 \pm 7.5$ & $.009^{\mathrm{S}}$ & & \\
\hline Range & 35-66 & $42-70$ & & & \\
\hline
\end{tabular}

Group I = NSTEMI with CKD, Group II = NSTEMI without CKD, S = Significant

$*_{t}$-test was done to measure the level of significance

Table-IV

Distribution of the study patients $(n=128)$ by mean serum creatinine and estimated GFR

\begin{tabular}{lcccccc}
\hline Variable & \multicolumn{2}{c}{ Group I $(\mathrm{n}=64)$} & & \multicolumn{2}{c}{ Group II $(\mathrm{n}=64)$} & \multirow{2}{*}{ p value* } \\
\cline { 2 - 3 } \cline { 5 - 6 } & Mean \pm SD & Range & & Mean \pm SD & Range & \\
\hline Serum creatinine(mg/dL) & $1.7 \pm 0.2$ & $1.5-2.8$ & & $1.0 \pm 0.1$ & $0.7-1.4$ & $.001^{\mathrm{S}}$ \\
$\begin{array}{l}\text { Estimated glomerular } \\
\text { filtration rate(mL/min/ }\end{array}$ & $40.4 \pm 8.8$ & $23-59$ & & $76.3 \pm 1.4$ & $60.7-131.9$ & $.001^{\mathrm{S}}$ \\
$\begin{array}{l}\left.1.73 \mathrm{~m}^{2}\right) \\
\mathrm{Hb} \%(\mathrm{gm} / \mathrm{dL})\end{array}$ & & & & & \\
\hline
\end{tabular}

Group I = NSTEMI with CKD, Group II = NSTEMI without CKD , S = Significant

$*_{t}$-test was done to measure the level of significance 
Table-V

Distribution of the study patients $(n=128)$ by site of coronary artery lesion

\begin{tabular}{|c|c|c|c|c|c|}
\hline \multirow[t]{2}{*}{ Site of Lesion } & \multicolumn{2}{|c|}{ Group I (n=64) } & \multicolumn{2}{|c|}{ Group II (n=64) } & \multirow[t]{2}{*}{ p value* } \\
\hline & $\mathrm{n}$ & $\%$ & $\mathrm{n}$ & $\%$ & \\
\hline LM, complex & 7 & 10.9 & 3 & 4.7 & $.323^{N S}$ \\
\hline \multicolumn{6}{|l|}{$\mathrm{LAD}$} \\
\hline Normal & 11 & 17.1 & 22 & 34.4 & $.127^{\mathrm{NS}}$ \\
\hline Proximal & 38 & 59.4 & 30 & 46.9 & \\
\hline Mid & 12 & 18.8 & 7 & 10.9 & \\
\hline Distal & 0 & 0 & 1 & 1.6 & \\
\hline $\mathrm{D}_{1}$ & 2 & 3.1 & 4 & 6.2 & \\
\hline $\mathrm{D}_{2}$ & 1 & 1.6 & 0 & 0 & \\
\hline \multicolumn{6}{|l|}{ LCX } \\
\hline Normal & 11 & 17.2 & 22 & 34.4 & $.118^{\mathrm{NS}}$ \\
\hline Proximal & 41 & 64.1 & 27 & 42.2 & \\
\hline Distal & 4 & 6.2 & 7 & 10.9 & \\
\hline $\mathrm{OM}_{1}$ & 3 & 4.7 & 3 & 4.7 & \\
\hline $\mathrm{OM}_{2}$ & 5 & 7.8 & 5 & 7.8 & \\
\hline \multicolumn{6}{|l|}{ RCA } \\
\hline Normal & 16 & 25 & 34 & 53.1 & $.056^{\mathrm{NS}}$ \\
\hline Proximal & 23 & 35.9 & 19 & 29.7 & \\
\hline Mid & 16 & 25 & 6 & 9.4 & \\
\hline Distal & 9 & 14.1 & 5 & 7.8 & \\
\hline
\end{tabular}

Group I = NSTEMI with CKD,Group II = NSTEMI without CKD,S = Significant,NS = Not Significant

*Chi-square test was done to measure the level of significance.

\section{Table-VI}

Distribution of the study patients $(n=128)$ by percentage of coronary artery lesion

\begin{tabular}{|c|c|c|c|c|c|}
\hline \multirow[t]{2}{*}{ Percentage of lesion } & \multicolumn{2}{|c|}{ Group I (n=64) } & \multicolumn{2}{|c|}{ Group II (n=64) } & \multirow[t]{2}{*}{ p value* } \\
\hline & $\mathrm{n}$ & $\%$ & $\mathrm{n}$ & $\%$ & \\
\hline \multicolumn{6}{|l|}{ Left main } \\
\hline Normal & 57 & 89.1 & 61 & 95.3 & $.323^{\mathrm{NS}}$ \\
\hline$<50 \%$ & 1 & 1.6 & 1 & 1.6 & \\
\hline$\geq 50 \%$ & 6 & 9.3 & 2 & 3.1 & \\
\hline \multicolumn{6}{|l|}{ LAD } \\
\hline Normal & 11 & 17.2 & 22 & 34.4 & $.089^{\mathrm{NS}}$ \\
\hline $50-75 \%$ & 1 & 1.6 & 3 & 4.7 & \\
\hline $75-99 \%$ & 44 & 68.8 & 33 & 51.6 & \\
\hline $100 \%$ & 8 & 12.4 & 6 & 9.3 & \\
\hline \multicolumn{6}{|l|}{ LCX } \\
\hline Normal & 11 & 17.2 & 22 & 34.4 & $.166^{\mathrm{NS}}$ \\
\hline $50-75 \%$ & 3 & 4.7 & 3 & 4.7 & \\
\hline $75-99 \%$ & 37 & 57.8 & 28 & 43.8 & \\
\hline $100 \%$ & 13 & 20.3 & 11 & 17.1 & \\
\hline \multicolumn{6}{|l|}{ RCA } \\
\hline Normal & 16 & 25 & 34 & 53.1 & $.052^{\mathrm{NS}}$ \\
\hline $50-75 \%$ & 5 & 7.8 & 1 & 1.6 & \\
\hline $75-99 \%$ & 31 & 48.4 & 17 & 26.5 & \\
\hline $100 \%$ & 12 & 18.8 & 12 & 18.8 & \\
\hline
\end{tabular}

Group I = NSTEMI with CKD, Group II = NSTEMI without CKD, NS = Not Significant

*Chi-square test was done to measure the level of significance. 
Table-VII

Distribution of the study patients $(n=128)$ by type of lesion

\begin{tabular}{|c|c|c|c|c|c|}
\hline \multirow[t]{2}{*}{ Type of Lesion } & \multicolumn{2}{|c|}{ Group I (n=64) } & \multicolumn{2}{|c|}{ Group II (n=64) } & \multirow[t]{2}{*}{$\mathrm{p}$ value } \\
\hline & $\mathrm{n}$ & $\%$ & $\mathrm{n}$ & $\%$ & \\
\hline \multicolumn{6}{|l|}{ LAD } \\
\hline Type A & 10 & 15.6 & 12 & 18.8 & $.059^{\mathrm{NS}}$ \\
\hline Type B & 21 & 32.8 & 20 & 31.2 & \\
\hline Type C & 22 & 34.4 & 10 & 15.6 & \\
\hline \multicolumn{6}{|l|}{ LCX } \\
\hline Type A & 9 & 14.1 & 13 & 20.3 & $.057^{\mathrm{NS}}$ \\
\hline Type B & 20 & 31.2 & 14 & 21.9 & \\
\hline Type C & 24 & 37.5 & 15 & 23.4 & \\
\hline \multicolumn{6}{|l|}{ RCA } \\
\hline Type A & 8 & 12.5 & 7 & 10.9 & $.052^{\mathrm{NS}}$ \\
\hline Type B & 13 & 20.3 & 5 & 7.8 & \\
\hline Tyре C & 27 & 42.2 & 17 & 26.6 & \\
\hline
\end{tabular}

Group I = NSTEMI with CKD, Group II = NSTEMI without CKD,NS = Not Significant

*Chi-square test was done to measure the level of significance

Table-VIII

Distribution of TIMI flow of the study patients $(n=128)$

\begin{tabular}{|c|c|c|c|c|c|}
\hline \multirow[t]{2}{*}{ TIMI flow } & \multicolumn{2}{|c|}{ Group I (n=64) } & \multicolumn{2}{|c|}{ Group II (n=64) } & \multirow[t]{2}{*}{ p value* } \\
\hline & $\mathrm{n}$ & $\%$ & $\mathrm{n}$ & $\%$ & \\
\hline \multicolumn{6}{|l|}{ LAD } \\
\hline Normal & 11 & 17.2 & 22 & 34.4 & $.175^{\mathrm{NS}}$ \\
\hline TIMI-0 & 7 & 11 & 4 & 6.2 & \\
\hline TIMI-1 & 15 & 23.4 & 9 & 14.1 & \\
\hline TIMI-2 & 29 & 45.3 & 26 & 40.6 & \\
\hline TIMI-3 & 2 & 3.1 & 3 & 4.7 & \\
\hline \multicolumn{6}{|l|}{ LCX } \\
\hline Normal & 11 & 17.2 & 22 & 34.4 & $.080^{\mathrm{NS}}$ \\
\hline TIMI-0 & 12 & 18.8 & 10 & 15.6 & \\
\hline TIMI-1 & 14 & 21.9 & 5 & 7.8 & \\
\hline TIMI-2 & 24 & 37.4 & 25 & 39.1 & \\
\hline TIMI-3 & 3 & 4.7 & 2 & 3.1 & \\
\hline \multicolumn{6}{|l|}{ RCA } \\
\hline Normal & 16 & 25 & 34 & 53.1 & $.054^{\mathrm{NS}}$ \\
\hline TIMI-0 & 14 & 21.9 & 13 & 20.3 & \\
\hline TIMI-1 & 15 & 23.4 & 4 & 6.2 & \\
\hline TIMI-2 & 16 & 25 & 12 & 18.8 & \\
\hline TIMI-3 & 3 & 4.7 & 1 & 1.6 & \\
\hline
\end{tabular}

Group I $=$ NSTEMI with CKD, Group II = NSTEMI without CKD NS $=$ Not Significant

*Chi-square test was done to measure the level of significance. 


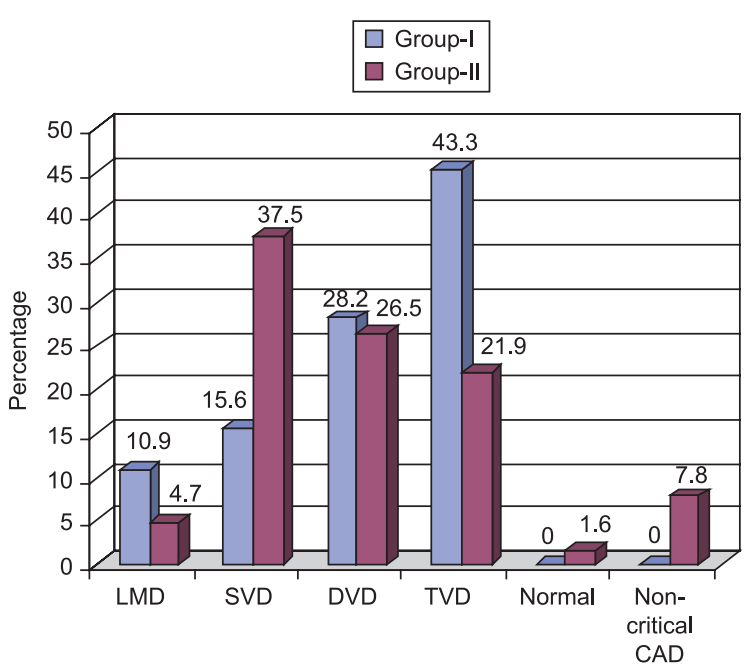

Fig.-1: Bar diagram showing distribution of the study patients $(n=128)$ by number of coronary artery involvement.

\section{Discussion:}

This was a prospective observational study. By analyzing the estimated GFR using the Cockroft and Gault formula, patients were categorized in two groups: group I - patients with NSTEMI with CKD and Group II - patients with NSTEMI with normal renal function. A total of 128 patients were included in this study.

When age of the study patients were compared between the groups, it was found that the mean age in group I was $60.4 \pm 8$ years (range: $45-74$ years) and group II was $49.9 \pm 9.3$ years (range: 31-70 years). Mean age difference was statistically significant $(\mathrm{p}<0.05)$ between the groups. Nearly similar pattern of age distribution was reported in different studies in Bangladesh like Pasha and Awal, et al. 4,9 It was evident from the study that patients with CKD tended to be older than those with normal renal function. This observation was being consistent with the findings of different studies done in foreign countries like Kang, Jeong and Kim $-62 \pm 9$ vs. $51 \pm 10$ years, Wong, et al. -63 vs. 53 years, Na, et al. $-62.3 \pm 12.4$ vs. $48.9 \pm 11.5$ years, Fox, et al. - 60 vs. 51 years and El-Menyar, et al. - 63 \pm 11 vs. $51 \pm 11$ years. $10,11,8,1,12$

Hypertension was the commonest risk factor in both groups. Wong, et al. found that among NSTEMI patients with kidney dysfunction $62.2 \%$ were hypertensive, $45.6 \%$ were diabetic, $31.3 \%$ were dyslipidaemic and $14.6 \%$ were current smoker in Canadian ACS I registry. ${ }^{10}$ Sarnak, et al., El-Menyar, et al., Fox, et al. and Kosuge, et al. observed hypertension as a commonest risk factor in their respective study. ${ }^{13,12,1,14}$ So, the prevalence of risk factors in the present study was comparable with other studies.
The mean left ventricular ejection fraction was $54.8 \pm 7.8 \%$ in group I and $58.5 \pm 7.5 \%$ in group II. Mean ejection fraction was lower in group I than group II. This difference was statistically significant $(\mathrm{p}<0.05)$. Pasha also showed that mean ejection fraction was significantly lower in patients with impaired renal function than those with

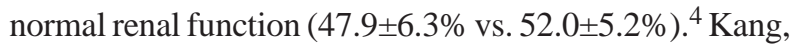
Jeong and Kim found that patients with NSTEMI with renal dysfunction had a significantly lower LVEF\% (51 $\pm 13 \%$ vs. $58 \pm 10 \%$ ). ${ }^{10}$ So, their findings were consistent with the findings of this study in that patients with CKD have reduced LVEF\% than those with normal renal function.

The mean value of serum creatinine and estimated glomerular filtration rate were $1.7 \pm 0.2 \mathrm{mg} / \mathrm{dL}$ and $40.4 \pm 8.8$ $\mathrm{mL} / \mathrm{min} / 1.73 \mathrm{~m}^{2}$ respectively in group I and $1 \pm 0.1 \mathrm{mg} / \mathrm{dL}$ and $76.3 \pm 1.4 \mathrm{~mL} / \mathrm{min} / 1.73 \mathrm{~m}^{2}$ respectively in group II. These differences were statistically significant $(\mathrm{p}<0.001)$. Hossain found identical mean serum creatinine and creatinine clearance rate $(1.73 \mathrm{mg} / \mathrm{dL}$ ranged from $1.5-2.5 \mathrm{mg} / \mathrm{dL}$ and $39.9 \mathrm{~mL} / \mathrm{min}$ ranged from $21-54 \mathrm{~mL} / \mathrm{min}$ respectively in 80 CKD patients) with the current study. ${ }^{15}$ Nearly similar pattern of mean serum creatinine and estimated glomerular filtration rate distribution were reported in different studies like Kang, Jeong and Kim, Wong, et al. and El-Menyar et al. ${ }^{10,11,12}$

Anaemia is common in CKD patients; it usually correlates with the severity of renal failure and contributes to many of the non-specific symptoms of CKD. In this study, mean $\mathrm{Hb} \%$ was $11.1 \pm 1.2$ and $12.1 \pm 1.1 \mathrm{gm} / \mathrm{dL}$ in group I and group II respectively which was statistically significant $(\mathrm{p}<0.05)$. Hossain found mean $\mathrm{Hb} \%$ was $11.6 \mathrm{gm} / \mathrm{dL}$ in $80 \mathrm{CKD}$ patients. $^{15}$

Coronary angiography is a frequent component of the care of ACS patients. ${ }^{5}$ After considering exclusion criteria total 152 patients were studied during hospital stay. But 128 of them underwent coronary angiography, among them 64 patients from group I and 64 patients from group II. Angiographic severity was assessed by evaluation of site of lesion, \% of stenosis, lesion morphology, TIMI flow grading and number of coronary artery involvement between the groups.

Majority of the lesions were distributed in the proximal segment of all major coronary arteries among the study group.

Regarding the type of lesions, type A lesion was found $18.8 \%, 20.3 \%$ and $10.9 \%$ in group I while $15.6 \%, 14.1 \%$ and $12.5 \%$ in group II of LAD, LCX and RCA respectively. 
Type B lesion was found $31.2 \%, 21.9 \%$ and $7.8 \%$ in group I while $32.8 \%, 31.2 \%$ and $20.3 \%$ in group II of $\mathrm{LAD}$, LCX and RCA respectively. In LAD type $\mathrm{C}$ lesion was found $34.4 \%$ in group I while $15.6 \%$ in group II. In LCX type C lesion was found $37.5 \%$ in group I while $23.4 \%$ in group II. In RCA type $\mathrm{C}$ lesion was found $42.2 \%$ in group I while $26.6 \%$ in group II. Type $C$ lesion was found more prevalent in both groups except in group II where type B lesion was found more prevalent in LAD. There were no significantly significant between the groups in terms of ACC/ AHA lesion classification ( $p>0.05$ ) that was consistent with the findings of Gibson, et al. and Kang, Jeong and Kim. ${ }^{16,10}$ TIMI flow 2 means good ante grade flow which was higher in both groups. TIMI flow difference were not statistically significantly ( $>00.05$ ) that was consistent with the findings of Gibson, et al. and Kang, Jeong and Kim. ${ }^{16,10}$

In group I, highest percentage had triple vessel disease 29 (45.3\%) followed by double vessel disease $18(28.1 \%$ ) and single vessel disease 10(15.6\%). By contrast, highest percentage had single vessel disease 24(37.5\%) followed by double vessel disease $17(26.6 \%)$ and triple vessel disease $16(25 \%)$ in group II. 7(10.9\%) and 3(4.7\%) had left main disease in group I and group II respectively. Noncritical coronary artery disease was found 5(7.8\%) in group II but none in group I. 1(1.6\%) had normal coronaries in group II but none in group I. Younger age was the strongest predictor of insignificant CAD in NSTEMI patients. ${ }^{17}$

Kang, Jeong and Kim studied 181 NSTEMI patients with CKD and normal renal function by coronary angiography and observed that the number of involved vessel was higher in patients with more severe renal dysfunction in contrast to the prevalence of 1 vessel disease was increased according to increased GFR. TVD was present significantly in higher proportion of patients with CKD than patients with normal renal function (29.5\% vs. $16.2 \%$, $\mathrm{p}<0.006$ ). The reverse was noted with respect to SVD, which were $54.4 \%$ in patients with normal renal function and $34.6 \%$ in patients with CKD $(\mathrm{p}<0.001) .{ }^{10} \mathrm{Na}$, et al. demonstrated three-vessel disease ( $40.6 \%$ vs. $16.6 \%$ ) and left main disease (13.7\% vs. $8.7 \%$ ) seemed to be more frequent in patients with CKD than those without CKD undergoing coronary angiography. ${ }^{8}$ The CAG findings of this study parallels the above two studies.

In patients with NSTEMI with normal renal function, cardiac catheterization reveals angiographically normal coronary arteries or mild disease (all lesions $<50 \%$ ) in $10 \%$ to $20 \%$ of patients, single vessel disease in $30 \%$ to $35 \%$, two vessel disease in $25 \%$ to $30 \%$, three vessel disease in $20 \%$ to $25 \%$, and left main artery disease in $5 \%$ to $10 \% .{ }^{18}$
In the study of Ali et al., CAG study of NSTEMI patients with normal renal function revealed that single vessel disease were $30 \%$, double vessel disease $36.67 \%$, triple vessel disease $20 \%$ and normal coronary artery $13.33 \% .{ }^{19}$ The higher incidence of multivessel coronary disease observed in the present study among patients with CKD may reflect a greater atherosclerotic burden than in patients with normal renal function.

Conclusions:

CKD strongly predicts severe coronary artery disease profile among NSTEMI patients. Compared to patients with normal renal function, CKD patients were significantly older, with a greater prevalence of hypertension, lower left ventricular ejection fraction and lower haemoglobin level. CKD was associated with an increased risk of triple vessel and left main disease. In contrast, the prevalence of single vessel disease was higher in patients with normal renal function. Other angiographic findings (TIMI flow, percent diameter stenosis, lesion classification) were not associated with GFR.

Study Limitations: Sample size was small. All the patients with NSTEMI with CKD were not included due to different contraindications and co-morbid conditions. All consecutive patients were not underwent coronary angiography.

\section{References:}

1. Fox, C.S., Muntner, P., Chen, A.Y., Alexander, K.P., Roe, M.T., Cannon, C.P., Saucedo, J.F., Kontos, M.C., Wiviott, S.D. Use of Evidence-Based Therapies in Short-Term Outcomes of ST-Segment Elevation Myocardial Infarction and Non ST-Segment Myocardial Infarction in Patients With Chronic Kidney Disease. Circulation, 2010; 121: 357-65.

2. Faruque, M., Islam, A.E.M.M., Rashid, M.A., Haque, M.S., Rahman, F., Kibria, M.G., Khan H.I.L.R. Coronary artery disease in patients with chronic kidney disease- a review. Cardiovascular Journal, 2008; 1(1): 97-104.

3. Chonchol, M., Whittle, J., Desbien, A., Orner, M.B., Petersen, L.A., Kressin, N.R. Chronic kidney disease is associated with angiographic coronary artery disease. American Journal of Nephrology, 2008; 28: 354-60.

4. Pasha, K. In-hospital outcome of patients of acute STEMI with impaired renal function. Thesis MD (Cardiology), National Institute of Cardiovascular Diseases (NICVD), Dhaka 2004.

5. Anderson, J.L., Adams, C.D., Antman, E.M., Bridges, C.R., Califf, R.M., Casey, D.E., Chavey W.E., Fesmire, F.M., Hochman, J.S., Levin, T.N., Lincoff, A.M., Peterson, E.D., Theroux, P., Wenger, N.K., Wright, R.S. ACCF/AHA 2007 Focused Update Incorporated into ACC/AHA 2007 guidelines for the management of patients with unstable angina/nonST-elevation myocardial infarction: a report of the American 
College of Cardiology/ American Heart Association Task Force on Practice Guidelines. Circulation, 2011; 123: 1-154.

6. K/DOQI clinical practice guidelines for chronic kidney disease: Evaluation, classification, and stratification. American Journal of Kidney Disease, 2002; 39: 1-266.

7. Cockcroft, D.W., Gault, M.H. Prediction of creatinine clearance from serum creatinine. Nephron, 1976; 16(1), 31-41.

8. Na, K.Y., Kim, C.W., Song, Y.R., Chin, H.J., Chae, D.W. The Association between Kidney Function, Coronary Artery Disease, and Clinical Outcome in Patients Undergoing Coronary Angiography. Journal of Korean Medical Science, 2009; 24(1): 87-94.

9. Awal, A., Hasan, S.A., Siddique, M.A., Subedi, B., Arzu, J., Ahmed, Q.A., Haque, K.M.H.S.S., Sultan, M.A.U., Islam, N. $\mathrm{N}$-Acetyl cystine for prevention of contrast induced nephropathy. University Heart Journal, 2009; 5(2): 57-59.

10. Kang, Y.U., Jeong, M.H., Kim, S.W. Impact of Renal Dysfunction on Clinical Outcomes of Acute Coronary Syndrome. Yonsei Medical Journal, 2009; 50(4): 537-45.

11. Wong, J.A., Goodman, S.G., Yan, R.T., Wald, R., Bagnall, A.J., Welsh, R.C., Wong, G.C., Kornder, J., Eagle, K.A., Steg, P.G., Yan, T. Temporal management patterns and outcomes of non-ST elevation acute coronary syndromes in patients with kidney dysfunction. European Heart Journal, 2009; 30(5): 549-57.

12. El-Menyar, A., Zubaid, M., Singh, R., Sulaiman, K., Thani, H.A., Akbar, M., Bulbanat, B., Hamdan, R.A., Mahmmed, W.A., Suwaidi, J.A. In-hospital Major Clinical Outcomes in Patients With Chronic Renal Insufficiency Presenting With Acute Coronary Syndrome: Data From a Registry of 8176 Patients. Mayo Clinic Proceedings, 2010; 85(4): 332-40.

13. Sarnak, M.J., Levey, A.S., Schoolwerth, A.C., Coresh, J., Culleton, B., Hamm, L.L., McCullough, P.A., Kasiske, B.L., Kelepouris, E., Klag, M.J., Parfrey, P., Pfeffer, M., Raij, L., Spinosa, D.J., Wilson, P.W. Kidney disease as a risk factor for development of cardiovascular disease- a statement from the
American Heart Association councils on kidney in cardiovascular disease, high blood pressure research, clinical cardiology, and epidemiology and prevention. Hypertension, 2003; 108: 2154-69.

14. Kosuge, M., Ebina, T., Hibi, K., Morita, S., Endo, M., Maejima, N., Iwahashi, N., Okada, K., Ishikawa, T., Umemuta, S., Kimura, K. An Early and Simple Predictor of Severe Left Main and/or Three-Vessel Disease in Patients with Non-ST-Segment Elevation Acute Coronary Syndrome. American Journal of Cardiology, 2011; 107: 495-500.

15. Hossain, M.S. Comparison of nephrotoxic effect of isoosmolar and low-osmolar non-ionic contrast media in patient with chronic kidney disease undergoing coronary angiography. Thesis MD (cardiology), National Heart Foundation Hospital \& Research Institute (NHFH \& RI), Dhaka 2010.

16. Gibson, C.M., Dumaine, R.L., Gelfand, E.V., Murphy, S.A., Morrow, D.A., Wiviott, S.D., Giugliano, R.P., Cannon, C.P., Antman, E.M., Braunwald, E. Association of glomerular filtration rate on presentation with subsequent mortality in non-ST-segment elevation acute coronary syndrome; observations in 13307 patients in five TIMI trials, European Heart Journal, 2004; 25: 1998-2005.

17. Patel, M.R., Chen, A.Y., Peterson, E.D., Newby, L.K., Pollack, C.V., Brindis, R.G., Gibson, C.M., Kleiman, N.S., Suacedo, J.F., Bhatt, D.L., Gibler, W.B., Ohman, E.M., Harrington, R.A. Prevalence, predictors, and outcomes of Patients with NonST-Segment Elevation Myocardial Infarction and insignificant coronary artery disease. American Heart Journal, 2006; 152(4): 641-47.

18. Meadows, T.A. Unstable Angina and Non-ST-SegmentElevation Myocardial Infarction. In: B.P. Griffin, E.J. Topol, eds. Manual of Cardiovascular Medicine. New Delhi: Wolters Kluwer Health, 2009; 28-48.

19. Ali, M.E., Siddique, M.A., Banerjee, S.K., Haque, K.M.H.S.S., Ahmed, Q.S., Rahmah, S.M.M., Ahmed, C.M. Coronary angiographic profile of the patients of Non Q wave and Q wave Myocardial Infarction: A comparative study. University Heart Journal, 2005; 1(1): 24-26. 